\title{
sciendo
}

\section{Leading teams in virtual environment during COVID-19 crisis}

\author{
Cristian Bogdan ONETE \\ Bucharest University of Economic Studies, Bucharest, Romania \\ cristian.onete@com.ase.ro \\ Sandra Diana CHIT,A \\ Bucharest University of Economic Studies, Bucharest, Romania \\ sandra.chita@yahoo.com, corresponding author \\ Irina ALBĂSTROIU \\ Bucharest University of Economic Studies, Bucharest, Romania \\ irina.albastroiu@com.ase.ro \\ Teodora Liliana ANDREI \\ Bucharest University of Economic Studies, Bucharest, Romania \\ teodora_liliana96@yahoo.com
}

\begin{abstract}
Team coordinators are prepared to manage multiple situations such as misunderstanding, conflicts, different levels of engagement and they are usually willing to take risks while accepting a leading position. Yet, not all of them are prepared for crisis such as COVID-19 pandemic. The way they communicate with their teams in this type of periods is essential to ensure continuity and establish organizational trust (Guzzo et al, 2021). In this context, many corporations had to face a new challenge: working mostly or even entirely from home. Employees as well as managers switched to virtual meetings, the concept of a team has suffered modifications and virtual meetings replaced all face-to-face interactions. Leaders had to adapt and learn how to improve their skills to engage with their teams and to ensure performance. The purpose of our study is to see what specific activities were implemented within teams while working from home, what is the perception leaders have about team performance and to find out if this context has diminished their level of control. Data for this paper are gathered using in-depth interviews with team leaders/coordinators/managers from different corporations installed in Bucharest, Romania. The results show that the performance has increased, the teams and coordinators showed a great adaptability, and their level of trust has improved. Recommendations are put forward for teams to consider creating a better balance between their personal and professional lives and to find new ways of socializing at work from time to time on other topics that the business-related ones.
\end{abstract}

Keywords: work from home, remote work, leadership, remote management, COVID-19.

\section{Introduction}

At the level of the European Union, about $5.4 \%$ of the able-bodied population worked from home in the period before the pandemic. Also, in Romania, before the pandemic time, only $0.8 \%$ of the labor force performed lucrative activity from home, being ranked on the last place among the EU countries (Ciocotisan, 2020). The impact of COVID -19 was felt on the labor market on the one hand with a contribution in increasing the unemployment rate in Romania, from 3.9 in October 2019 to 5.3 in October 2020 (Sava, 2021). On the other hand, the actual working time decreased, and not least the rate of those who worked from home increased, on average, to about $37 \%$ of the total active workforce in the European Union. Romania, which in turn was under the influence of the pandemic, had 20\% more employees who worked from home. However, Romania has 
maintained the same tendency to be the last among employees working from home, compared to other countries in the union (Ciocotisan, 2020).Also, in America, the percentage of those working from home has risen rapidly since the first month of the COVID-19 pandemic, from $3.4 \%$ to $43 \%$ (Feitosa \& Salas, 2020).

The behavior of employees at work compared to that manifested at home is more prosocial and characterized by more conscientiousness (Grover \& Furnham, 2021). Adapting from office work to work from home can be quite difficult for many of the employees who found themselves in this position in 2020, because professional life interferes with personal life. The balance between parental responsibilities and work has always been a challenge for employees who have children in care (Lin \& Burgard, 2018). This change, brought about by the pandemic, can be even more difficult for employees who are in the position of parents, taking into account the fact that their children also have to go to school online during this period. However, an interesting initiative comes from the HoReCa industry, the most affected of the industries during the pandemic, namely work from hotel as an alternative to work from home (Business Insider SRL, 2020).

If before the pandemic the leaders could control the activity of the employees under their eyes, and implicitly the efficiency of the activity as a whole, working from home comes as a challenge for them to coordinate their team remotely and maintain efficiency. Studies presented by Business Insider SRL (2020b), have shown that the most important skill of leaders in the pandemic period is to maintain the motivation and commitment of subordinates. At the other end of the spectrum of skills that leaders need to have in the context of working from home is conflict mitigation, given the limited contact between employees. Other skills that should define the leader in remote employee control are trust, responsibility, goal-setting, providing direction and guidance to employees, and maintaining team spirit. What changes is the way the leader adapts and implements these skills while working from home (Business Insider SRL, 2020b).

At the company level, the transition to the work from home system must be treated with the utmost responsibility, so that the activity can be carried out without interruptions and safety from the point of view of information security. During the work from home, the impact of IT assistance companies on the development of the activity is much more important than before, in order to ensure the continuity of the work, in case of technical problems with the devices. The risk of being the victim of a cyberattack is another aspect that should not be neglected. The careful choice of communication channels for confidential information, antivirus systems, and especially the careful training of employees in this regard are essential aspects for business security (Romania Crisis Center, 2020).

\section{Literature review}

With the advent of the COVID-19 pandemic, more and more researchers have begun to study the impact it produces in various spheres of the economy, in the light of attempts by countries around the world to combat its spread. The labor market is among the most affected branches, a fact confirmed by an unemployment rate, in Romania, at the end of the third quarter of 2020 of 5.2\% (INS, 2021), although declining compared to the second quarter, much higher compared to that recorded in recent years. More precisely, the unemployment rate in recent years has had a decreasing trend, from $4.8 \%$ in 2016 , to $4 \%$ in 2017 , then to $3.3 \%$ in 2018 and $2.9 \%$ in 2019 , respectively. The emergence of the pandemic has reversed this declining trend, making the unemployment rate almost double in 2020 compared to the previous year (INS, 2020). Moreover, another sign of the negative impact of COVID-19 on the labor market is the 50 percent decrease 
in gross domestic product, from $4.2 \%$ in 2019 to $2.1 \%$ in 2020 , at the level of Romania (Sava, 2020). This decrease was caused by the closure of factories during quarantine periods, and the entry of staff into technical unemployment.

Technology has made possible the beginning of the notion of working from home, since 1980, but this opportunity was viewed, at that time, rather with skepticism on the part of business leaders, amid the inability to control the productivity of their employees. at home. 39 years later, the percentage of those working from home was tiny, about $10 \%$, but the pandemic brought a change of mentality (David \& Raju, 2021, p. 30). Forced by long periods of isolation at home, many organizations have resorted to the so-called work from home, a concept too little exploited until then, to continue their work. This change was a challenge for some employees while for others it came naturally, depending on their skills and previous experiences working from home. On the other hand, lack of experience can generate additional effort, even of a material nature, for organizations consisting in providing trainings on remote work techniques and even the necessary equipment for the activity (Amit \& Karen, 2020).In accordance with the above, Hasan et al. (2021), states that more than the internet access and the endowment with the necessary equipment, "proper training and upgrading of worker skills" are the key to the survival of enterprises during the pandemic.

Before the COVID-19 pandemic, work sometimes crept into employees' homes even after the 8-hour schedule, through important emails that required a response (Capitano \& Greenhaus, 2018). If until now people found refuge, after the time spent at work, through social activities with friends or family, now the need to work from home has more and more diminished the possibility of disconnection. Moreover, the stress in the case of people working from home is about 2 times higher compared to those who work outside the home. Over time, as the balance between work and personal life decreases, mental imbalances, depressions occur, which is why both employees and organizations must make constant efforts to combat work-related stress and maintain mental well-being. of employees (Vasudevan et.al., 2021). In line with the above, Brian Kropp, vice president of a senior research group, says in an interview that working from home creates a sense of loneliness / isolation for employees through the lack of social interactions in the office (David \& Raju, 2021, p. 30). In addition, another concern for the health of employees is lack of physical exercise, the comfort of the couch is a behavior that over time leads to obesity, muscle atrophy and other negative implications (David \& Raju, 2021, p.33). From a sociodemographic point of view, Griffin et al. (2002) show that both genders have a higher risk of suffering from depression in the context of low control at work.

While some researchers have focused on the downside of working from home, Kropp has identified a number of benefits for employees who have joined this type of work. The most important advantage for the employee being a decrease in costs. Other advantages may be less control from superiors or even the possibility of not having a rigid work schedule according to office work, depending on the nature of the activity (David \& Raju, 2021, p. 32). In addition, the activity at work based on innovation, contributes to the stimulation of the employee from a cognitive point of view, by using the knowledge acquired at work, in activities outside the workplace (Lukoschek \& Homburg, 2021). Golden (2021), shows that for some of the employees who go to work from home, there is an improvement in the balance between time spent at home and work time, depending on how they manage the two activities.

There is a trend among employees working from home to live or move to residential neighborhoods mostly occupied by people who have the same occupation, namely working from home, thus forming a community of home workers, out of a desire to socialize and share ideas on 
common themes (Zenkteler et. al., 2019).An interesting aspect of the long-term work model from home, from Kropp's perspective, is the removal of geographical barriers. Specifically, the employee can work from home, for a company either of their country, or of another country than that without having to change their place of residence. However, this type of flexibility for employees can interfere with the level of staff turnover in some companies. Other factors that could influence fluctuation may be lower development opportunities in the company for employees working from home and lack of diversity (David \& Raju, 2021, pp. 34-35).

Under the COVID-19 pandemic, the digitization process has taken a considerable lead. In the industrial and service sectors, new technologies are an essential tool in the 21 st century (Roblek, et. al., 2020). The need to move much of your daily work from the online workplace, such as online schooling and homework, has facilitated this process. Although the HoReCa industry was hard hit (Volkmann et. al., 2021) by the closure of its premises and accommodation spaces, and by travel restrictions, the employees in the back office of these units did not stop working. They moved their activity in the online environment, working from home, in order not to lose contact with potential customers, in the hope that things will recover at some point (Chadee et al., 2021).

An issue of working from home from the perspective of managerial positions was addressed by Newman and Ford (2020), as a challenge for leaders to maintain the performance of the team and the company by acting remotely. Based on studies and research, they identified five stages through which managers can coordinate their teams more efficiently while working from home. Thus, a first stage refers to the understanding by employees of what the new reality means. The actions that should be undertaken by the manager in the first stage are: organizing weekly meetings, both at team and individual level, in which the manager shows interest and empathizes with the new situation (Newman \& Ford, 2020, pp. 2-4). Each employee adapts differently to this new reality and there is a higher risk of conflicts by communicating between employees in the online environment, compared to face to face (Reyes et. al., 2020). In fact, managerial functions have a major impact on the longevity of employees in the company, through the way they manage the activity and contribute to the formation of links between employees, and between employees and the organization (Rubenstein et al.2020). The second stage refers to the trust that the manager inspires in the employees and to the way in which he encourages the company's culture. Here are three strategies that can interfere with employees' confidence in their leader, namely: organizational, leadership, and team-level (Newman \& Ford, 2020, pp. 4-6). In fact, studies show that the leadership style adopted by managers impacts the results of employees at work (Shkoler \& Tziner, 2020).

Furthermore, the third stage involves the adaptation of leaders to the new virtual communication platforms. Face-to-face communication is mediated in the context of working from home through platforms such as Zoom, Skype or WebEx. However, a less discussed issue is addressed by Haesevoets et. al (2020): the communication between manager and employee made through email, using the BCC function negatively influences the team dynamics, as opposed to using the $\mathrm{CC}$ function. The fourth stage consists in the professional development of the team members, by delegating managerial tasks to those employees that the manager considers competent based on their performances, thus stimulating creative thinking (Newman \& Ford, 2020 , pp. 8-9). And the fifth and last stage involves the integration in the organization's processes of periodic audits, through which to follow the acquisition of the company's culture and mission by its staff, and the leadership skills of the leader. Following the audit, actions must be taken that will be taken in accordance with the result obtained (Newman \& Ford, 2020, p. 9). This audit 
could also include issues related to the company's COVID-19 prevention actions, an issue that many employees are currently concerned about (Radulescu et. al., 2021).

\section{Methodology}

This research paper analyzes the impact of the implementation of work from home for a manager or team leader/coordinator and how it affected the efficiency and performance on a team level. The purpose of this scientific article is to examine what type of actions were taken during the COVID-19 pandemic and what tools were used. The hypothesis of this research is that the control level of managers/ team leaders was not affected, and performance of the team has increased during work from home while the feeling of belonging to a group has diminished. This paper uses a qualitative method and summarizes findings from one-to-one interview with 6 team leaders/ managers activating in multinational companies installed in Bucharest, Romania, five women and a man. The in-depth interviews have been conducted in January 2021 in a virtual format in order to respect restrictions imposed by the current health crisis. We used a structured interview which has been distributed via e-mail to all participants and we have also scheduled meetings using Teams platform or phone in order to further develop some of the aspects they have mentioned in their answers. The interviewees were open to share their experiences during this difficult time, as well as practices they might have used to make things work. The approach of this paper is based on the challenges as well as good practices we can use while working from home. First, we wanted to discover who are the people we interview and that motivates them in their daily work. The objective of this study is to see if the performance and collaboration of teams have been impacted because of the switch to work from home. Subsequently recommendations were made for the teams in discussion as well as for leading from work from home in general.

\section{Results and discussions \\ Profile of the interviewed people}

The interviews for our research were held in January 2021, 10 months after the lockdown was declared in Romania. Economy has suffered major modifications during this time and the first thing that was implemented in the environments who allowed it was work from home. We interviewed 5 people working in Bucharest, Romania, all of them under 40 years old. In order to understand how the migration of their activity to work from home environment was possible, we needed to find out what are their companies' activities (Figure 1). The team leaders/ managers are coming from two different companies, 4 of them work in energy management and automation environment while the $5^{\text {th }}$ is working for a shared service center for banking. Our purpose was to have more people from the shared service center for banking, therefore a second person has been contacted via e-mail, but no answer has been received.

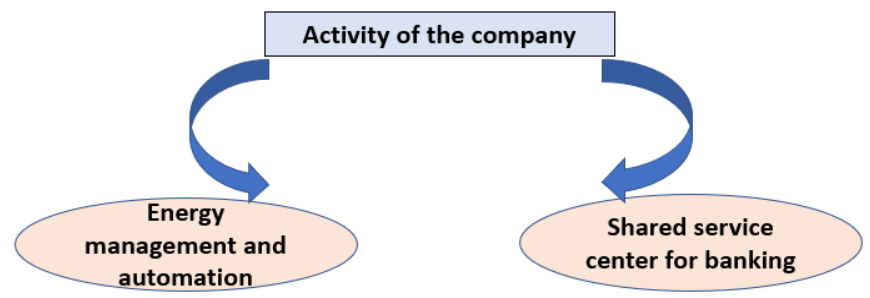

Figure 1. The activity of the companies where the interviewed people work

Source: Authors' own research.

DOI: 10.2478/picbe-2021-0031, pp. 328-337, ISSN 2558-9652 |

Proceedings of the $15^{\text {th }}$ International Conference on Business Excellence 2021 
Once we found out what their companies' activities are about in general, we went into details concerning the departments for which they and their teams work, and we have summarized their answers in Figure 2.
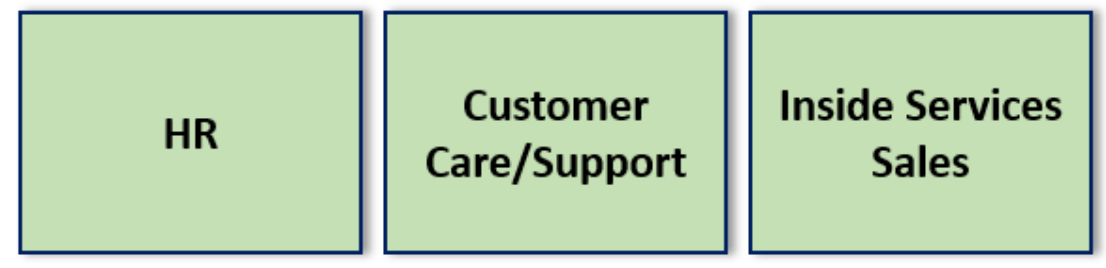

PICBE |

333

Figure 2. Departments of the concerned teams

Source: Authors' own research.

From the 5 team leaders, just 3 of them have more than two years of experience in their current role (Figure 3). When asked what they like the most about their current role, the team leaders mentioned different aspects: the variety of tasks, the direct impact they can have when taking a decision, the exciting combination of different key elements involved such as projects, countries, businesses, the development of people and coaching them towards achieving their career plan, offering support and guidance, changing opinions, suggesting improvement, implementing ideas but also caring about people.

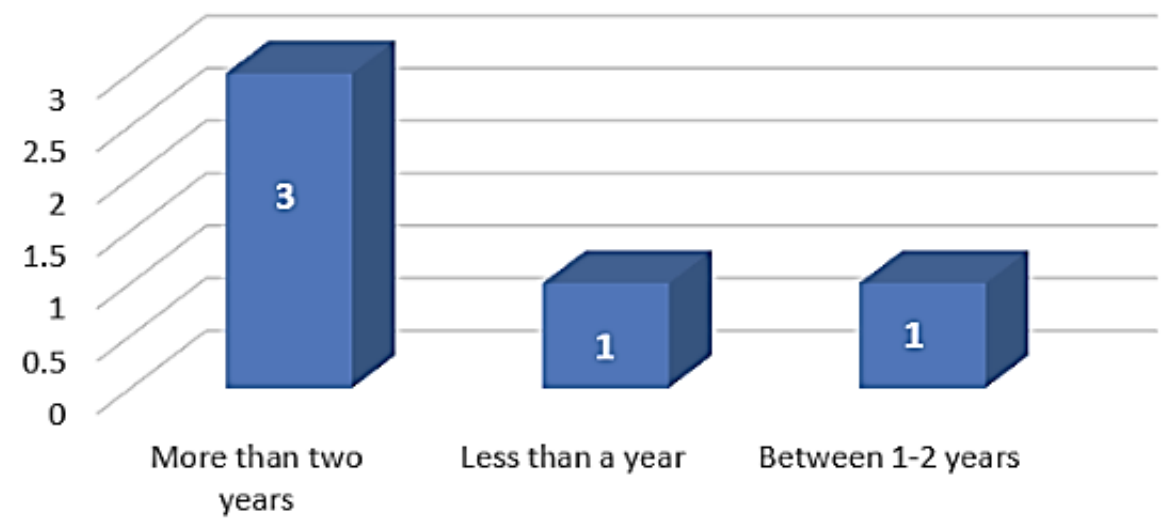

Figure 3. Experience of the interviewed people in their current role

Source: Authors' own research.

\section{Habits before the pandemic}

The 5 people we interviewed are leading teams of different sizes, it starts from 3 (plus 3 others as dotted line manager) and it goes up to 25 people. In order to see if they were prepared to switch to a virtual leading environment, we wanted to find out what were their habits in terms of working from home before the pandemic. Even though they had this possibility, they wouldn't all necessarily take this opportunity, affirming that they preferred to go to the office or that they were using this option less than 5 times a year. The lack of confidence in the viability of the system was an issue. One of the team coordinators had a different role before the pandemic that made work from home easy because she was mostly working online with people from other countries. As ways to keep in contact with their teams before the pandemic, they were using different tools: phone, Skype for Business (chat and calls). 
To improve collaboration between individuals and increase team spirit, team buildings were part of the work before the pandemic. All participants confirmed they used to have team buildings before pandemic on a company level as well as on team levels sometimes: team outings, fun activities organized by the company, coffee with CEO etc.

Also, they used to meet daily face to face (exception being the work from home days) and on a business level, team meetings or one to ones were organized weekly, biweekly or monthly depending on the needs.

PICBE |

334

\section{Leading from home}

All interviewed people have switched to work from home when the lockdown was installed in Romania. Some of them are currently working in a hybrid format, from home but also from the office. Even though flexibility has seen its level increased during the pandemic, only one person out of 5 has been working from another place, his native country, while the others affirmed, they stayed in Bucharest through the whole period.

Also, the pattern of meetings has changed. For example, a practice was to have two daily calls of 15 up to 30 minutes in order to replace coffee breaks as well as one weekly business meeting. The frequency of the virtual meetings has decreased with time as well as the use of camera which is not mandatory. The team meetings are sometimes just operational or just to keep in contact with each other. The means of communication are: MS Teams, Skype for Business, Whatsapp, Facebook Messenger, Kudoboard for birthdays, surveys via Form or phone.

In order to improve collaboration, different practices were put in place. For instance, ice breakers such as "How are you feeling today" (give a grade from 1 to 10). This strategic is used for two reasons, because it is difficult to see the people's mood when you are not face to face and it is also a tool to engage people in the call. Other practices aim to strengthen the team spirit: one hour of games, tea breaks, meeting at the end of the year to celebrate the good things that happened to people in 2020.

None of the team leaders interviewed feels less in control working from home from a performance point of view, but it is more difficult to observe if the individuals in the team are doing well so in this case the open communication becomes very important. People management based only on verbal communication was a challenge that leading people had to face. A study shows us that in a virtual format it is more difficult for people who are not used to be very autonomous and also the feeling of belonging to the company is not as strong for the virtual teams (Reyes, Luna \& Salas, 2020). Nonetheless, the performance was good, and they do not take into consideration how many breaks people take if they deliver things on time. Also, they mentioned that it is easy to see who is actually working and who is not even in a virtual form and as long as the work is done and business is not affected there is no need to check on people for example if they are connected. In some cases, performance increased and catch up meetings as well as leveraging reporting turned out to be helpful.

\section{Conclusion}

On $16^{\text {th }}$ of March 2020 Romania has entered in lockdown in order to protect the population. Restrictions made multinational companies with office activities make the decision to switch to $100 \%$ work from home. As a consequence of this, many things had to be adjusted: VPNs, security programs, collaborative tools as well as providing devices to employees (laptops, phones, headsets etc.). The new ways of working needed new actions in order to ensure continuity and efficiency of work and security of the business. All the people we interviewed 
have adapted to virtual environment very quickly. They feel secure knowing that the tools will support $100 \%$ because they have been tested and work from home is now part of an official agreement. One of the people we interviewed was the point of contact for tool issues in the beginning of the pandemic and he explained how complicated it was. Meanwhile the infrastructure was improved via servers and licenses.

To conclude our research shows that pandemic didn't affect performance neither the feeling of the control on a business level, but it has altered the collaboration between people, made verbal and open communication a key element of daily work and has erased the barrier between personal and professional life, people feeling free to reach out to each other at any hour and on many channels. It is more difficult to keep track on tasks using multiple channels and working overtime has created expectations that are not sustainable on a long term. We recommend team leaders to focus on the wellbeing of their teams, engage in relaxing activities from time to time and encourage individuals in setting a good balance between personal and professional life. As a limit of our research, it would have been interesting to have team leaders' opinions when the lockdown started and compare them to now, as well as to ask employees for their opinions to see how things are perceived from their position. In a future research we would like to study what are employees as well as their managers' opinion on remote work, how is it perceived and what would be the reasons people are still reluctant to the possibility of working from another city or even country/continent, as well as what would be the implications especially on the economic level.

\section{References}

Amit, K., and Karen, Z.K. (2020). The potential impact of the Covid-19 pandemic on occupational status, work from home, and occupational mobility, Journal of Vocational Behavior, No. 119.

Business Insider SRL (2020a). Is work from home difficult? Try the Work from Hotel alternative in Bucharest, Available at: https://www.romania-insider.com/p-work-home-difficult-trywork-hotel-alternative-bucharest, Accessed: 31.01.2021.

Business Insider SRL (2020b). Comment: Maintaining efficiency in times of remote working and COVID-19 - What are the most important leadership skills for Leaders to succeed? Available at: https://www.romania-insider.com/comment-maintaining-efficiency-timesremote-working-and-covid-19-what-are-most-important-leadership, Accessed: 31 January 2020 .

Capitano, J., and Greenhous, J.H. (2018). When work enters the home: Antecedents of role boundary permeability behavior, Journal of Vocational Behavior, Vol. 109, 87-100.

Chadee, D., Ren, S., and Tang, G. (2021). Is digital technology the magic bullet for performing work at home? Leasson learned for post COVID-19 recovery in hospitality management, International Journal of Hospitality Management, Nr. 92.

Ciocotisan, B. (2020). Analysis: Work from home before and after the pandemic. How COVID-19 has transformed the labor market, Available at: https://www.1asig.ro/Analiza-Munca-deacasa-inainte-si-dupa-pandemie-Cum-a-tranformat-COVID-19-piata-fortei-de-muncaarticol- 3, 102-64180, htm, Accessed: 31 January 2021.

David, J. F., and Raju, P.S. (2021). The work-from-home trend: An interview with Brian Kropp, Business Horizons, No. 64, 29-35.

Feitosa, J. and Salas, E. (2020). Today's virtual teams: Adapting lessons learned to the pandemic context. Organizational Dynamics. 
Golden, T.D. (2021). Telework and the Navigation of Work-Home Boundaries, Organizational Dynamics.

Griffin, J.M., Fuhrer, R., Stansfeld, S.A., and Marmot, M. (2002). The importance of low control at work and home on depression and anxiety: do these effects vary by gender and social class? Social Science \& Medicine, 54(5), 783-798.

Grover, S., and Furnham, A. (2021). Personality at home vs work: Does framing for work increase predictive validity of the Dark Triad on work outcomes? Personality and Individual Differences, Vol. 169.

Guzzo, R.F., Wang, X., Madera, J.M., \& Abbott, J.A. (2021). Organizational trust in times of COVID-19: Hospitality employees' affective responses to managers' communication, International Journal of Hospitality Management, 93, [102778].

Haesevoets, T., Cremer, D., and McGuire, J. (2020). How the use of Cc, Bcc, forward, and rewrite in email communication impacts team dynamics, Computers in Human Behavior, Vol. 112.

Hasan, S.M., Rehman, A., Zhang, W. (2021). Who can work and study from home in Pakistan: Evidence from a 2018-19 nationwide household survey, World Development, Vol. 138.

INS (2020). In the third quarter of 2020, the employment rate of the working age population (15-64 years) was $66.0 \%$, increasing compared to the previous quarter. Press release, No. 333/22 December 2020, https://insse.ro/cms/sites/default/files/com_presa/com_pdf/ somaj_tr3r_20.pdf, Accessed: 21 January 2021.

INS (2021). http://statistici.insse.ro:8077/tempo-online/\#/pages/tables/insse-table, Accessed: 21 January 2021.

Lin, K.Y., and Burgard, S.A. (2018). Working, parenting and work-home spillover: Gender differences in the work-home interface across the life course, Advances in Life Course Research, Vol. 35, 24-36.

Lukoschek, C.S., and Homburg, R.M.S. (2021). Integrating Home and Works: Hoe the Work Environment Enhances Household-Sector Inovations, Research Policy, 50(1).

Newman, S.A., and Ford, R.C. (2020). Five Steps to Leading Your Team in the Virtual COVID19 Workplace, Organizational Dynamics.

Radulescu, C.V., Ladaru, G.-R., Burlacu, S., Constantin, F., Ioanăș, C., and Petre, I.L. (2021) Impact of the COVID-19 Pandemic on the Romanian Labor Market, Sustainability, 13(271).

Reyes, D.L., Luna, M., and Salas, E. (2020). Challenges for team leaders transitioning from faceto-face to virtual teams, Organizational Dynamics.

Roblek, V., Bach, M.P., Meško, M., and Bertoncel, T. (2020). Best Practices of the Social Innovations in the Framework of the E-Government Evolution, Amfiteatru Economic, 22(53), 275-302.

Romania Crisis Center (2020). Working from home during COVID-19. Available at: https://www.pwc.ro/en/romania-crisis-centre/technology/working-from-home-duringcovid-19--1-.html, Accessed: 1 February2021.

Rubenstein, A.L., Peltokorpi, V., and Allen, D.G. (2020). Work-home and home-work conflict and voluntary turnover: A conservation of resources explanation for contrasting moderation effects of on-and off-the-job embeddedness, Journal of Vocational Behavior, No. 119. 
Sava, J.A. (2020). GDR forecast for Romania due to the coronavirus outbreak 2019-2021. Available at: https://www.statista.com/statistics/1106069/covid-19-impact-on-gdp-growth -romania/, Accessed: 10 February 2021.

Sava, J.A. (2021). Labor market indices in Romania, including COVID-19 impact 2019-2020. Available at: https://www.statista.com/statistics/1119871/romania-labor-market-indica tors/, Accessed: 9 February 2021.

Shkoler, O., and Tziner, A. (2020). Leadership Styles as Predictors of Work Attitudes: A Moderated - Mediation Link. Amfiteatru Economic, 22(53), 164-178.

Vasudevan, M., Sangeeta, M., Subburaj, A., Athul, K.B. (2021). Work from home in the pandemic era: Loss of mental equilibrium?, Asian Journal of Psychiatry, No. 55.

Volkmann, C., Tokarski, K.O., Dincă, V.M., and Bogdan, A. (2021). The Impact of COVID-19 on Romanian Tourism. An Explorative Case Study on Prahova County, Romania, Amfiteatru Economic, 23(56), 196-205.

Zenkteler, M., Darchen, S., Babiano, I.M., and Baffour, B. (2019). Home-based work in cities: In search of an appropriate urban planning response, Futures. 